\title{
Explicar, valorar, comprender e influir: en torno a la "actuación" del historiador en la Historia de las Relaciones Internacionales
}

\author{
ENTREVISTAS A VARIOS AUTORES*
}

2

\section{RESENTACIÓN}

En las discusiones que los coordinadores sostuvimos para preparar este número 37 de la Revista de Relaciones Internacionales, surgieron problemas que afectaban a la Historia, otros que afectaban a la Teoría de Relaciones Internacionales, y otros cuyo efecto abarca toda la teoría social y política. Discusiones sobre las fuerzas profundas, el evento/acontecimiento, y la influencia relativa de ambos; sobre narrar desde el presente, pero contextualizando los actos y discursos de los protagonistas en su lugar en el tiempo y en el espacio; entre otras.

Una de estas discusiones - muchas veces dilemáticas- se refería a la responsabilidad y la culpabilidad (moral) en la Historia; otra discusión recurrente era el papel del historiador en una época en la que hasta los medios de comunicación más rancios usan términos como narrativas.

Ciertamente los discursos, las narrativas y los relatos crean realidad e identidad, y a nadie se le escapa que, hoy por hoy, lograr que una narrativa sea hegemónica es un triunfo político de primer orden.

Pero, aunque muchas personas se sienten autorizadas a sentenciar sobre la Historia - y a la misma Historia - en una tertulia o en una columna de prensa, los trabajos de los profesionales son, como mínimo, la referencia - de lo que no es simplemente inventado. $Y$ ahí está nuestra responsabilidad como estudiosos y académicos.

Como teníamos claro que no resolveríamos las cuestiones -incluso que algunas de ellas no tienen solución- decidimos preguntar a colegas historiadores y de relaciones internacionales sobre estas últimas preocupaciones.

He aquí las respuestas que nos han llegado y que agradecemos de todo corazón.

Los coordinadores
* Entrevistas realizadas por: Eduardo $A$. CARREÑO LARA, Pedro A. MARTÍNEZ LILLO,

Jesús NIETO GONZÁLEZ Y Francisco J. PEÑAS ESTEBAN

DOI: http://dx.doi.org/ 10.15366/relacionesinternacionales2018.37.008

\section{LAS PREGUNTAS}

Como nos enseña el gran maestro Edward H. Carr, todos hacemos historia desde el presente $^{1}$, apelando a categorías y/o valores que nos constituyen como personas. Del mismo modo, conocemos más de los acontecimientos y procesos históricos de índole internacional que, incluso, aquellos que fueron sus propios protagonistas.

1 CARR, Edward H., ¿Qué es la historia?, Editorial Ariel, Barcelona, 2010. 


\section{En palabras de Adam Schaff:}

"El historiador (sujeto cognoscente) es un hombre como cualquier otro y no puede librarse de sus características humanas: no está en disposición de pensar sin las categorías de un lenguaje dado, posee una personalidad condicionada socialmente en el marco de una realidad histórica concreta, pertenece a una nación, a una clase, a un medio, a un grupo profesional, etc., con todas las consecuencias que todo esto implica en el plano de los estereotipos que acepta (en general inconscientemente), de la cultura de la que es a la vez creación y creador, etc."2

El presente, en definitiva, es nuestra coyuntura histórica, por lo cual, no podemos obviar los problemas que enfrentamos; ni menos las valoraciones morales. Así, el historiador sólo puede mostrarse consciente de ellas, a fin de intentar explicarlas en su trabajo.

Obviamente, no buscamos proyectar nuestras categorías. Por el contario, siguiendo a Quentin Skinner (Ideas in Context) ${ }^{3}$ y Reinhart Koselleck ("historia de los conceptos") ${ }^{4}$, intentamos situarnos en las mentalidades dominantes en el tiempo, lugar y situación del objeto de estudio.

Al respecto, os invitamos cordialmente a comentar estas reflexiones, tomando en consideración las siguientes tres preguntas:

- Describimos procesos internacionales y sus consecuencias, pero ¿es lícito hacer una valoración moral de éstos?

- ¿Qué responsabilidad tenemos como historiadores en las repercusiones políticas, sociales, etc. de lo que narramos?

- ¿Debemos medir y, eventualmente, evitar aquellos temas que -en teoría- debilitan nuestras convicciones, y fortalecen a los "adversarios"?

2 SCHAFF, Adam, Historia y verdad. Ensayo sobre la veracidad del conocimiento histórico, Editorial Grijalbo, México DF, 1982, p. 341

3 SKINNER, Quentin, "Meaning and Understanding in the History of Ideas", in History and Theory, Vol. 8, N 1, 1969, pp. 3-53.

4 KOSELLECK, Reinhart, The Practice of Conceptual History. Timing History, Spacing Concepts, Stanford University Press, Stanford, 2002. 


\section{María José BECERRA \\ Universidad Nacional Tres de Febrero, Argentina \\ Diego BUFFA \\ Universidad Nacional de Córdoba/CONICET, Argentina}

\section{Describimos procesos internacionales y sus consecuencias, pero ¿es lícito hacer una valoración moral de éstos?}

Es una pregunta compleja, que posee varias dimensiones. Apriorísticamente, si nos quedamos en el nivel "descriptivo" de los procesos internacionales y sus consecuencias, la primera respuesta desde lo metodológico es que este tipo de investigación no posibilita ningún tipo de valoración o no debería posibilitarla ya que sólo implica la narración relacionada de los atributos o características que posee el objeto bajo estudio. Sin embargo, esta afirmación no es tan taxativa, si la analizamos teniendo en cuenta por un lado, el carácter propio de las ciencias sociales en general, y en este caso en particular de la Historia y de las Relaciones Internaciones; y por el otro, el proceso de construcción del objeto de estudio. En el primer caso, como señala Pedro Demo, las ciencias sociales son intrínsecamente ideológicas permitiendo la justificación política de las posiciones sociales. Con ello se legitiman, se mantienen y se maximizan las estructuras de poder vigente. Es así, que "la ideología, que aparece como instrumento inicial al servicio de los dominadores" ${ }^{\prime \prime}$, para poder dar respuestas que se adecuen a sus necesidades debe distorsionar la realidad, reforzando su situación de dominación. Pero, a su vez, es posible la construcción de otro tipo de respuestas desde la posición de los sectores dominados, la existencia de otras "miradas" sobre una realidad que es social e histórica, y sobre la cual se avanza más allá de la mera descripción para así poder analizar sus propias contradicciones y conflictos. Por otra parte, la construcción del objeto de estudio en ciencias sociales es de una identidad tal entre el sujeto cognoscente y el sujeto/objeto a conocer, que es imposible que no exista una modificación recíproca entre ambos durante el proceso investigación. Según Aguirre Rojas, esto hace que el investigador social (en su caso un historiador) se involucre en el proceso social que analiza, poniendo en cuestión la idea tradicional de neutralidad y objetividad. Sin embargo, advierte sobre el error de estudiar procesos históricos -o internacionales- del pasado con valores y modos de ver actuales ${ }^{6}$. Este anacronismo, impediría ver la dinámica propia que posee la realidad social, esto se salva con el ejercicio arduo y constante que debe hacer el investigador para desarrollar su "capacidad de extrañamiento y autoexilio intelectual" de sus propias circunstancias históricas y de sus valores.

\section{¿Qué responsabilidad tenemos como historiadores en las repercusiones políticas, sociales, etc. de lo que narramos?}

Esta pregunta nos remite a otros interrogantes: ¿Para qué hacer Historia? ¿Cuál es su finalidad? ¿Para qué sirve y cuál es su función? ¿La Historia tiene solo un fin pedagógico?, es decir, "aprender del pasado para comprender el presente". Esta visión solo nos permite

5 DEMO, Pedro (1975), Investigación participante. Mito y realidad. Buenos Aires: Editorial Kapeluz, p. 14

6 AGUIRRE ROJAS hace referencia a que hay que ser cuidadosos de analizar el pasado con valores propios de la sociedad capitalista en la que vive el investigador. Esta idea puede extrapolarse al análisis de sociedades contemporáneas que no se desenvuelven bajo los mismos valores culturales y/o religiosos. 
explicar los acontecimientos del presente, pero no analizar su organización actual. Debemos tener en cuenta que la Historia cumple una función destacada en la confrontación ideológica que se produce entre los sectores dominantes y dominados de una sociedad. En tal sentido, Pereyra postula, que hay una "separación forzada entre el saber histórico y el horizonte político en el que ese saber se produce"7. Se podría señalar, que hay una función teórica de la Historia (explicar los procesos sociales) y su función social (organizar el pasado en función de los requerimientos del presente) que se complementan, aunque no está carente de fricciones. El historiador consciente de esta dualidad, es aquel que produce un saber histórico cuyo fin es emancipatorio. Es por ello que es responsable de producir un conocimiento que muestre la conflictividad, las tensiones y los cambios sociales, pero no lo es en la aplicación de las políticas públicas que puedan o no generarse por sus investigaciones, eso se encuentra en otra esfera.

\section{¿Debemos medir y, eventualmente, evitar aquellos temas que -en teoría- debilitan nuestras convicciones, $y$ fortalecen a los "adversarios"?}

Claramente, no. Según Jacques Le Goff ${ }^{8}$, la Historia es la forma científica de la memoria colectiva, por lo tanto el historiador que busca analizar los procesos sociales, culturales, políticos, económicos, etc. de una sociedad debe buscar las tensiones, las contradicciones en cada una de estos ámbitos para así poder (re)construir el pasado, estudiar el presente y comprenderlo. Como señalamos anteriormente, la objetividad y la neutralidad absoluta frente al objeto de estudio, no existe. La propia "construcción" de ese objeto, la selección de los elementos de la realidad social para ser analizados por parte del historiador, dan cuenta de esto. Más aún, si tenemos en cuenta el componente ideológico que subyace en ello. Es así que una Historia aséptica, donde el historiador no tome partido, no se involucre, ni se apasione con lo investigado es una idea que ha quedado en el pasado. Se deben investigar todos los temas, indagando las "grietas", las situaciones conflictivas que hacen que la realidad observable social e histórica sea compleja.

\section{Referencias}

AGUIRRE ROJAS, Carlos (2005), Antimanual del mal historiador. Rosario: Editorial Prohistoria. DEMO, Pedro (1975), Investigación participante. Mito y realidad. Buenos Aires: Editorial Kapeluz. LE GOFF, Jacques (1991), El orden de la memoria. El tiempo como imaginario, Barcelona: Paidós. PEREYRA, Carlos (2004). ¿Historia para qué?, México: Editorial Siglo XXI.

\section{Paloma GARCÍA PICAZO}

Universidad Nacional de Educación a Distancia, España

\section{Describimos procesos internacionales y sus consecuencias, pero ¿es lícito hacer una valoración moral de éstos?}

El hecho de "describir" implica una acción cognitiva sujeta a condicionamientos tanto físicopsíquicos -orgánicos, psicológicos- como culturales -individuales y sociales- por parte del

\footnotetext{
7 PEREYRA, Carlos (2004). ¿Historia para qué?, México: Editorial Siglo XXI., p. 24

8 LE GOFF, Jacques (1991), El orden de la memoria. El tiempo como imaginario, Barcelona: Paidós.
} 
sujeto que la ejerce y que, en un sentido no determinista, implica una serie de presunciones -asunciones previas- que afectan al propio hecho de "describir" en el sentido que su hipotética objetividad. Esta objetividad de la descripción se valida mediante pruebas de tipo teórico - congruencia hipotético-deductiva-, empírico - congruencia hipotético-inductiva-, facilitándolo la comunicación con el medio científico, susceptible de trascender la dimensión subjetiva, valorativa, etc. (T.S. Kuhn; A. F. Chalmers; H. Maturana y F. Varela). A ello se agrega necesariamente la dimensión lingüística intrínseca a la naturaleza de la comunicación humana, en este caso, en el sentido preciso de formular descripciones ajustadas a la realidad en un lenguaje científicamente homologable y virtualmente unívoco (L. Wittgenstein; G. Steiner). Valorar los procesos internacionales -cuando ya el término "proceso" supone una elección epistémica determinada: no todos los teóricos/analistas lo contemplan-, no sólo es posible sino lícito en términos de una libertad de juicio inherente al propio conocimiento que, por su parte, nunca es "neutral", lo que limita/matiza las pretensiones - a veces infundadas - de "objetividad" (I. Kant; Jesús Ibáñez). En perspectiva ética y moral, "valorar" responde a unos parámetros que, eventualmente, pueden ser "universales/universalizables", precisando en todo caso los límites axiológicos de tal acción, lo que los relativiza y circunscribe al momento, lugar y coordenadas intelectuales, afectivas, sociales, culturales y civilizatorias del sujeto emisor de la valoración.

\section{¿Qué responsabilidad tenemos como historiadores en las repercusiones políticas, sociales, etc. de lo que narramos?}

Siendo esta responsabilidad un hecho cierto que cada autor de "relatos históricos" pretendidamente objetivos debe asumir plenamente, tampoco cabe ignorar la repercusión social y política que eventualmente tal narrativa implica, en particular, al vulgarizarse en medios de comunicación masificados ( $H$. Arendt; J. Habermas; M. Horkheimer). En tal sentido opera la ideologización -autónoma o heterónoma; espontánea o inducida; libre o interesada- del discurso histórico. Existen historiadores que operan guiados por su propia ideología, asumida de forma libérrima pero también instrumental o interesada y que construyen relatos dirigidos a confirmar sus propias presunciones; de paso, sirven a confirmar presunciones, prejuicios, asunciones, etc. de otros miembros de la comunidad académica que comparten ideas/ ideología afines (concepto de ideología: K. Mannheim; H. Arendt), así como de otros grupos y sectores sociales con intereses, tácitos o expresos, en propagar interpretaciones históricas semejantes; papel ejercido a menudo por científicos "a sueldo" -tácito, público- de ciertas instituciones. Sólo un cultivo de la Historia en sentido "verdadero" -Escuela de los Annales, por ejemplo- resulta emancipador, en la medida en que trasciende lo aparente, lo asumido, lo convenido, cuestionándolo, hasta indagar en la verdadera índole del acontecer, histórico mediante un análisis crítico y un examen reflexivo profundo, aplicando una metodología rigurosa y exhaustiva, capaz de revisar a fondo cuantos errores históricos, conveniente manipulados y deformados, hubieran enturbiado el propio proceso del conocimiento histórico de cualquier realidad internacional. Las "Comisiones de Historiadores" que revisaron las relaciones históricas entre Alemania y Polonia, por ejemplo, tras la II Guerra Mundial, darían un buen ejemplo. 
¿Debemos medir y, eventualmente, evitar aquellos temas que -en teoría-debilitan nuestras convicciones, y fortalecen a los "adversarios"?

Quien obre así debería ser expulsado, preferiblemente de forma ostensible, de la comunidad científica en la que pretendidamente estuviera incluido, sin más. Semejante actuación sólo revela su nula preparación y su incompetencia científica, así como una falta de ética profesional y personal. Las teorías, hipótesis, construcciones teóricas, etc. más veraces no se verifican en puridad mediante la simple contienda entre autores pertenecientes a "escuelas" -a menudo, interesados, acríticos y doctrinarios partícipes de un perverso juego de ventajas, premisos, reconocimientos, ascensos, etc.: P. Bourdieu, Homo Academicus, entre otros-, sujetas estas querellas además a la infinita complicación de los "juegos del lenguaje" (L. Wittgenstein), sino que la apetecida veracidad se sustancia mediante análisis y escrutinios donde el objetivo prioritario es esa "búsqueda sin término" (K.R. Popper; M. Bunge; A.D. Sokal) de la adecuación entre "conocimiento" y "realidad".

\section{Joaquín FERMANDOIS}

Pontificia Universidad Católica de Chile

\section{Describimos procesos internacionales y sus consecuencias, pero ¿es lícito hacer una valoración moral de estos?}

Entre las tareas del historiador internacional - o de cualquiera otra especialidad historiográficaestá la de mostrar las consecuencias que los procesos y las acciones humanas poseen para las valoraciones de los implicados y para aquellas de los historiadores. Lo que es importante no confundir la escritura de la historia con la predicación y el lenguaje profético, en sumas cuentas, con un moralismo. Preguntas y contrapreguntas con la máxima honestidad posible, eludiendo las sucesivas "prohibiciones de preguntar" - de pensar- constituyen un mandato para el historiador y en general para aquel que tenga a la a ciencia desde la región de las humanidades y las ciencias sociales.

Dos paradigmas nos sirven de ilustración. Uno es el diálogo de los Melos de Tucídides, siempre considerado la quintaesencia del realismo político, algo ajeno a la valoración. Primero, es dudoso que el renunciar a la valoración se esté más cerca de la "realidad", o se aleja de la complejidad de esta. De lo que se desprende, segundo, que Atenas a pesar de este "realismo" perdió la guerra. El resultado de este conflicto fue el debilitamiento de la civilización helénica. Ello, ¿constituyó un bien para la experiencia humana?

Segundo, se trata del paradigma de la Segunda Guerra Mundial, el relato político moral que está más en el corazón de la modernidad, en todo caso del siglo XX. Aquí hay más unanimidad en el sentido de que no basta con la popular y jabonosa consigna de que "la historia la escriben los vencedores". En especial pocos dudan de la centralidad del Holocausto como definitoria de un carácter de la guerra, y el mito -en sentido positivo, arcaico si se quiere- moral de nuestra era, sin el cual nos empobrecemos como civilización. Ello no quiere decir que sea la única pregunta moral. En otra dimensión, en un momento hay que preguntarse por Nanjing, la persistencia de Gulag, los bombardeos indiscriminados a ciudades, Hiroshima. 
¿Qué responsabilidad tenemos como historiadores en las repercusiones políticas, sociales, etc., de lo que narramos?

No tenemos la responsabilidad del político o del hombre de acción. La responsabilidad es la del hombre de ciencia, la pensar - en pensamiento histórico- con honestidad a través de la escritura de la historia. Actuar ante la repercusión histórica es propio al sujeto de la acción, que solo ocasionalmente es un historiador; ilustrar acerca de los peligros y de las perspectivas de la condición histórica es el papel de historiador, o de toda persona históricamente educada.

¿Debemos medir y, eventualmente, evitar aquellos temas que -en teoría-debilitan nuestras convicciones, $y$ fortalecen a los "adversarios"?

Sería asumir la posición de apologista, permisible en la polémica pero que al final distorsiona el conocimiento. Para la misma fortaleza de nuestras convicciones, se deben asumir con sentido crítico -es decir, analítico, pensable- los temas o problemas que ponen en cuestión o podrían erosionar nuestros valores. Hay que dar una respuesta, en la cual es imposible que nuestras posiciones no se vean algo enturbiadas, o de otro modo se incrementará más la vulnerabilidad de nuestras interpretaciones o valoraciones. Quizás, cuando uno defiende valoraciones que son minoritarias dentro de los portadores de la disciplina, se pude dedicar más energía (tiempo, cantidad de trabajo, destacar lo que para muchos parece poco relevante) pero no esconder el sol con la mano.

Sucede - me ha sucedido- que se exagera en términos de intensidad y a veces de cantidad, un enfoque y ciertos temas o problemas, porque consideramos que no han recibido suficiente atención. Y en ello puede haber una atención excesiva, mirada aisladamente, pero no una injusticia.

\section{Laura FERNÁNDEZ DE MOSTEYRÍN \\ Universidad de Educación a Distancia de Madrid, España}

\section{Describimos procesos internacionales y sus consecuencias, pero ¿̇es lícito hacer una valoración moral de éstos?}

Más que como historiadora, que no lo soy, yo hablo desde las ciencias sociales, cuya tarea primera sería describir y tratar de explicar los hechos sociales a partir del método científico, de manera lógico-racional y a partir del examen riguroso de las evidencias disponibles. En este sentido, habría que evitar los juicios de valor. Hay otra ciencia social cuya epistemología es distinta y no pretende ser "neutral" sino comprender desde el punto de vista de los sujetos y su método puede ser igualmente riguroso.

Pienso sin embargo que las ciencias sociales deben ser reflexivas ante el objeto y ante el método. Todos los objetos de estudio y el modo de mirarlos tienen un contexto. En cada momento hay una serie de problemas que se consideran importantes, que son relevantes para alguien, y otros que no. Estudiarlos y no hacerlo puede tener consecuencias para otros/ as etc. En la medida en que ese ejercicio es necesario, es posible que ya estemos entrando en el terreno de los juicios de valor. Diría entonces que, eligiendo nuestros temas de trabajo y el modo de enfocarlos, tomando postura epistemológica estamos también haciendo juicios morales sobre el tipo de sociedad deseable y ello no es incompatible con el rigor en la tarea 
intelectual. Con un ejemplo muy básico: el método del físico es y sólo puede ser neutral; pero el físico o el experto puede decidir no aplicarlo a la bomba atómica o, en nuestro tiempo, a las armas autónomas. En las ciencias sociales el razonamiento podría ser similar. El método puede ser lo más riguroso, sistemático e incluso "neutral"; pero no así la agenda de investigación. Además, mi campo de especialización está ligado al estudio del poder y su distribución. Por eso, soy consciente $-y$ creo que parte del oficio es serlo-, de que enunciar, nombrar y explicar entraña un poder.

En fin, estudiar los hechos sociales desde distintas perspectivas y con la mejor evidencia posible es nuestra obligación. Hacer de ello una forma de "activismo" o de implicación para transformar la sociedad es una elección profesional y moral que corresponde a cada investigadora. Mi visión particular de la ciencia social está marcada, entre otras, por la obra de C. W. Mills quien decía que la primera tarea del intelectual era poner de manifiesto las causas del "malestar". Entiendo que cualquiera de mis actividades debe estar orientada al interés público, a mostrar el poder y a señalar los problemas que van más allá de los individuos. Hacer eso significa hacer constantes juicios de valor y posicionarse. Pero no es tanto en el desarrollo del método sino en el diseño de la agenda, en las elecciones de tu trayectoria y en las decisiones sobre las condiciones de investigación.

\section{¿Qué responsabilidad tenemos como historiadores en las repercusiones políticas, sociales, etc. de lo que narramos?}

De nuevo hablo desde la Sociología o desde su intersección con la Ciencia Política. Desde luego creo que tenemos responsabilidad. Independientemente de las cuestiones éticas que puedan surgir en nuestras investigaciones, pues creo que no es el núcleo de la pregunta, creo que cuando decidimos que un problema merece ser estudiado, lo estamos nombrando y lo estamos haciendo relevante. Cuando decidimos desde qué paradigma o de qué modo lo vamos a examinar, determinamos algunas dimensiones a estudio y dejamos de atender a otras. $Y$ esas elecciones sobre el objeto y el método tienen potencial para modificar la realidad.

C. W. Mills decía que la Historia la hacen quienes tienen los medios de hacer la Historia. Y en cada época, hay unos medios de hacer la Historia. En nuestra sociedad contemporánea, occidental, secular y del "conocimiento", la ciencia y la academia son instituciones en las que se ejerce mucho poder y cuyo potencial para transformar la realidad es muy alto, aunque no lo sea en todos los campos. En el mío concreto - que es el estudio sociopolítico de la seguridad y sus políticas-, la academia puede ser muy influyente en políticas. Si parte de nuestra tarea es localizar, describir, explicar cómo se distribuye el poder en términos sociopolíticos -en cada momento y lugar-, y determinar dónde están los medios de "hacer Historia" -en cada momento-; entonces del poder de la ciencia y de la academia en nuestra sociedad y de nuestra posición en ella, se deriva nuestra responsabilidad.

\section{¿Debemos medir y, eventualmente, evitar aquellos temas que -en teoría-debilitan nuestras convicciones, y fortalecen a los "adversarios"?}

En coherencia con mi razonamiento anterior, yo diría que si de verdad consideras que un problema debe ser estudiado porque es de interés público, aunque desafíe algún tipo de poder, o si lo estudias precisamente por ello -sobre todo por ello-, el rigor es esencial. 
Un mejor conocimiento será el que contenga un esfuerzo por buscar mejores evidencias, someter a juicio tus propias posiciones, hipótesis y argumentos. Por otro lado, pienso que, además del rigor en el método, en esta tarea es esencial la autonomía y la independencia. No se trata de construir "contra otros" sino de construir y explicar por qué un objeto es de interés público, y por qué arrojar luz sobre él es bueno en sí mismo. Si comprender mejor significa constatar que una estaba equivocada en sus posiciones y que hay que reenfocar parte o todo del estudio del problema, sea.

\section{Ricardo Martín DE LA GUARDIA \\ Universidad de Valladolid, España}

\section{Describimos procesos internacionales y sus consecuencias, pero ¿̇es lícito hacer una valoración moral de éstos?}

No solo por el hecho de analizar y concluir sobre procesos internacionales relevantes históricamente, sino que en general, el historiador en tanto se enfrenta a acontecimientos del pasado, introduce inevitablemente un criterio moral en sus consideraciones. La imagen del pasado y del mundo característica de un momento histórico que el científico social conforma y hace suya en un trabajo incluye una forma de entenderlos en el que su formación personal, entendida esta en un sentido amplio -esto es, sus inquietudes intelectuales y políticas, los saberes adquiridos o heredados - forjan una estructura de conocimiento a partir de la cual la interpretación que lleva a cabo supone otorgar o dar un valor moral al objeto de su reflexión, ya sea de forma implícita, ya explícita, máxime en el caso de las Relaciones Internacionales, donde el conflicto y la guerra son elementos constantes o, al menos, reiterativos, y donde por tanto, la radicalidad de la condición humana se muestra en toda su crudeza, por lo que la valoración moral en este caso es un hecho: viene dada casi por definición.

No creo que lo dicho hasta aquí sea una mera especulación, pues basta con reparar en cualquier texto clásico o actual que verse sobre un episodio o proceso histórico internacional para comprobar que incluso los más descriptivos incluyen, de una u otra forma, una valoración moral sobre lo acontecido. No se trataría tanto, pues, de abordar la "licitud" como la inevitabilidad del criterio moral. La Historia de las Relaciones Internacionales no es "neutral", y menos aún en sus análisis sobre las realidades históricas más próximas, ya que en este caso lo que se trata de explicar está enclavado en procesos de muy larga duración y que llegan hasta el momento en el que está viviendo el historiador y que influyen sobre él y sobre su forma de ver y pensar.

En todo caso, la consideración "moral" no tiene por qué restar objetividad o cientificidad al análisis.

¿Qué responsabilidad tenemos como historiadores en las repercusiones políticas, sociales, etc. de lo que narramos?

Si entendemos como responsabilidad directa, teniendo en cuenta nuestra condición de historiadores, y aunque, como hemos indicado al final de la respuesta anterior, en algunas ocasiones vivimos en un medio que es consecuencia directa de los procesos que estudiamos, no existe una responsabilidad en lo que narramos. Procedemos al análisis riguroso del pasado 
con métodos y objetivos definidos con el fin de comprehender lo ocurrido, pero no para actuar sobre las consecuencias que lo ocurrido haya provocado. Por tanto, la responsabilidad del historiador de las Relaciones Internacionales está directamente vinculada con su profesionalidad, en tanto en cuanto adecuamos nuestra labor a los objetivos trazados para ofrecer una explicación global y coherente. La responsabilidad es pues personal, vinculada a la honradez intelectual de cada historiador.

Otra cuestión es la utilización que otros actores implicados en el conocimiento o en la acción sobre la realidad internacional hagan o puedan hacer sobre los trabajos del historiador, como lo son también las abiertas manipulaciones que teóricos o historiadores de las Relaciones Internacionales han llevado a cabo en función de unos intereses que no son científicos, sino que están al servicio de ideologías, estados, poderes o, sencillamente, economías. Por poner tan solo un ejemplo, son bien conocidas algunas de las burdas interpretaciones que, durante el enfrentamiento de bloques de la Guerra Fría, para justificar determinadas políticas, se hicieron sobre episodios históricos de trascendencia internacional.

\section{¿Debemos medir y, eventualmente, evitar aquellos temas que -en teoría-debilitan nuestras convicciones, y fortalecen a los "adversarios"?}

Si se trata de un enfrentamiento y unos adversarios puramente intelectuales, no solo no debemos evitar ciertos temas sino abordarlos de tal manera y con tal éxito, mediante análisis de fuentes y argumentación, que ofrezcamos una alternativa sin dejar de ser lo suficientemente humildes para reconocer que son posibles otras perspectivas, siempre y cuando se apoyen en un aparato teórico y crítico sólido. Precisamente, el verdadero avance en el conocimiento de la historia en general y de la Historia de las Relaciones Internacionales en particular está estrechamente relacionado con el enriquecimiento que proporcionan nuevas fuentes, nuevos métodos, nuevas aproximaciones y conclusiones sobre la realidad que se estudia. Se trata, pues, de procurar el contraste no de opiniones superficiales, a las que en esta sociedad del espectáculo estamos acostumbrados, sobre cuestiones internacionales -ese sería el verdadero adversario, que simplifica hasta el absurdo la realidad internacional-, sino de interpretaciones fundamentadas en un análisis contrastado y riguroso.

No solo no deben evitarse los temas favoritos de los "adversarios", sino ninguno en general, ya que el conocimiento mediante el estudio es uno de los más eficaces modos de intentar mejorar el mundo y la sociedad en que vivimos. En el origen del mal está la ignorancia.

\section{María Inés MUDROVCIC}

Universidad Nacional de Comahue/CONICET, Argentina

\section{Describimos procesos internacionales y sus consecuencias, pero ¿es lícito hacer una valoración moral de éstos?}

Los revisionismos o reinterpretaciones de procesos históricos constituyen un claro ejemplo de la base normativa que permea la labor historiográfica. No importa cuán distante esté ese proceso del presente del historiador que lo reconstruye pues, de cualquier modo, la carga valorativa estará siempre presente. Tomemos por caso el rol desempeñado por el general J. A. Roca en el proceso de la constitución del estado-nación argentino. Hasta casi mediados 
de los 80 del siglo pasado, Roca fue considerado un héroe nacional y su llamada "Campaña del Desierto", una gesta que logró incorporar nuevas tierras al territorio argentino. No existe un pueblo o ciudad en la Patagonia que no posea una calle llamada Roca o un monumento consagrado en su honor y hasta una ciudad recibió su nombre. A mediados de los 80 y con la incipiente democracia, J. A. Roca se transforma en el emblema del genocidio perpetuado a los pueblos originarios. La historia del proceso de la constitución del estado-nación vuelve a reescribirse. Otro caso paradigmático lo constituye la revisión del proceso que condujo a la Revolución Francesa al cumplirse un centenario de la misma, y podríamos continuar nombrando ejemplos.

¿Por qué sucede esto así? No es porque hayan aparecido nuevos datos o documentos. Un proceso histórico es una reconstrucción que presupone una teleología en la que lo que se quiere explicar - la constitución del estado-nación argentino o la Revolución Francesa, por ejemplo- opera como cierre discursivo que le otorga sentido retrospectivo. El cierre, llamado técnicamente consecuencia, confiere significación moral en tanto que relaciona en una estructura significativa a los acontecimientos (condiciones o causas) con respecto al grupo social al que está dirigido y al que provee de representaciones acerca de sus orígenes. La estructura temporal del proceso encuentra en la narración su expresión discursiva. No se trata de emitir juicios de valor sobre los procesos históricos así reconstruidos, sino de asumir una actitud ético-crítica del contexto social y político del presente que los originan.

\section{¿Qué responsabilidad tenemos como historiadores en las repercusiones políticas, sociales, etc. de lo que narramos?}

Quisiera mencionar dos tipos de intervenciones, entre otras posibles, que los historiadores pueden generar en la esfera pública: una es a través del impacto o repercusión social o política que sus obras puedan tener, y otra es la injerencia directa que, como partisanos, realizan en la esfera pública. El primer caso lo podemos ejemplificar con los debates llevados a cabo luego de la publicación de las obras de D. Goldhagen y J. T. Gross y, el segundo caso, con el Manifiesto de los Historiadores en Chile de 1999 o el debate de los historiadores Historikerstreit- ocurrido en Alemania a mediados de los 80.

Los Verdugos Voluntarios de Hitler escrito por Golhagen a principios de 1996 y la primera edición polaca de Los Vecinos de J. T. Gross publicada a mediados de 2000, no sólo provocaron fuertes debates historiográficos sino obtuvieron grandes repercusiones en el público no especializado. Aunque el primero de ellos fue ampliamente rechazado por los historiadores, tuvo, sin embargo, un gran apoyo de intelectuales como R. Berenstein y J. Habermas e impactó fuertemente en las discusiones públicas. En 1997 recibió el Premio Democracia por, entre otras cuestiones, haber "dado un impulso fundamental a la conciencia pública de la República Federal de Alemania". El libro de J. T. Gross, al contrario, se basó en un exhaustivo análisis de las fuentes y no fue criticado por sus colegas sino que fue condenado por los ciudadanos polacos. El libro de Gross derribó el "mito polaco": no fueron los nazis los que mataron a los judíos polacos del pueblo de Jebwabne en 1941, sino sus propios vecinos antisemitas. El 10 de julio de 2001, el presidente polaco A. Kwasbniewski pidió perdón público ante una plaza casi vacía. Tanto el libro de D. Goldhagen como el de T. Gross tuvieron, luego de publicados, fuertes repercusiones políticas y sociales en la esfera pública. Sus obras fueron usadas públicamente - al decir de Habermas - como referencias 
normativas en la comprensión de sus respectivos presentes. En estos casos, los historiadores no poseen responsabilidad alguna del impacto político-ideológico que sus trabajos pudiesen causar y fueron escritos con independencia de los mismos.

Diferente es el caso del uso partisano de la historia. El Manifiesto de los Historiadores de Chile publicado en 1999 o el debate de los historiadores -Historikerstreit- ocurrido en Alemania a mediados de los 80 , constituyen ejemplos de cómo los historiadores informados por su disciplina intervienen en la esfera pública. En el caso del Manifiesto, en respuesta a una carta escrita por Pinochet en 1998; en el segundo caso, intentando dar cuenta del fenómeno del nazismo a las nuevas generaciones de alemanes. Los historiadores en tanto ciudadanos y partisanos informados se involucran en el terreno político ideológico del presente. En estos casos son enteramente responsables del uso público que hacen de su disciplina, de la misma forma que un biólogo lo es discutiendo acerca de políticas públicas sobre el cambio climático o un médico sobre el aborto, por ejemplo.

¿Debemos medir y, eventualmente, evitar aquellos temas que -en teoría- debilitan nuestras convicciones, $y$ fortalecen a los "adversarios"?

En una situación ideal de habla, las personas que sostienen posiciones opuestas acerca de un tema debieran poder entrar en diálogo bajo el presupuesto de que siempre prevalecerá el mejor argumento. Es decir, durante el diálogo se debieran presentar las mejores evidencias de cada una de las partes, no evitar temas, escuchar objeciones y, eventualmente, abandonar la convicción propia si uno es convencido por los argumentos del adversario. Es lo que Gadamer denomina "estar abierto a la opinión del otro". Sin embargo, cuanto más central es la situación, más difícil es su tratamiento en estos términos. El conflicto entre "nosotros" y "ellos" (nuestros adversarios) es muy profundo, no porque sus convicciones sean incomprensibles o incoherentes para nosotros, sino porque presuponen valores incompatibles con los nuestros. En estos casos, las discrepancias no pueden resolverse reclamando una postura que apele a la razón como legitimación última. En las situaciones en las que ninguna postura puede apelar a nada que la legitime por sobre las otras, muchas veces, la única salida que aparece es la de la violencia. Pensemos en los recientes acontecimientos ocurridos a raíz del referéndum de independencia en Cataluña, o las muertes acaecidas en el contexto del reclamo de tierras del pueblo Mapuche en Argentina o la violencia ejercida contra afroamericanos en EEUU, por nombrar sólo algunos casos. Estos ejemplos muestran no sólo la debilidad de la promesa de la política para disipar y aclarar estos conflictos profundamente atravesados por convicciones dispares acerca de cómo deben desempeñarse los asuntos humanos en la espera pública, sino también, el casi nulo desarrollo de la tolerancia hacia los "otros" en nuestras actuales sociedades. A propósito de esta cuestión, le pregunté a un colega argentino ultrakischnerista si estaría dispuesto a abandonar sus convicciones si un adversario político le ofreciera mejores argumentos, a lo que me respondió: "iSí, por supuesto, pero todavía no he encontrado ninguno!" 


\title{
José Luis NEILA HERNÁNDEZ
}

\author{
Universidad Autónoma de Madrid, España
}

\section{Describimos procesos internacionales y sus consecuencias, pero ¿es lícito hacer una valoración moral de éstos?}

La Filosofía y, en particular, la Historia conjetural del siglo XVIII se planteaba no sólo como un ejercicio de construcción de conocimiento en pro de la verdad, en el sentido moderno, sino también de una evocación de una moralidad que pretendía mejorar la vida de hombres y mujeres. Este sustrato de conocimiento y moralidad anida en la base de todas las utopías de la modernidad. Con la emancipación del científico social y del propio oficio de historiador respecto de la Filosofía en el curso del siglo XIX el positivismo elevó al altar del conocimiento el mito de la objetividad. Con éste se orillaría la dimensión ética del "científico social". Una inercia y una práctica que sería objeto de profunda crítica por los filósofos neokantianos frente al positivismo. En el curso del siglo XX una de las cuestiones fundamentales en el pensamiento filosófico y de la propia construcción de conocimiento fue el relativismo, pero el cuerpo central del desarrollo de la construcción del conocimiento científico se parapetaría, en el marco del giro estructuralista, en la universalidad del método científico. Sólo a partir del giro antropológico y la socialización de la "angustia" posmoderna se fueron insertando en el debate y la construcción del conocimiento científico otras pautas de acción y pensamiento que despejarían el camino al universo subjetivo y la compleja paleta ética que emana del científico social, y del historiador, en su existencia social. Karl Popper y Thomas Khun lejos de pincelar escenarios antagónicos se ofrecían como dos dimensiones complementarias en torno al modo de cómo se ha o se debe de hacer ciencia - como filósofo de la ciencia, en el primer caso- y cómo se hace la ciencia según los diferentes contextos históricos - como historiador de la ciencia, en el segundo-.

En mis años de formación allá por los años ochenta siempre me resultó incómodo el dogma de fe de algunos de mis docentes de la licenciatura de Historia que, parapetados aún en la fortaleza del historicismo y el mito de la objetividad, denostaban y desanimaban cualquier gesto hacia al estudio de los problemas no ya actuales sino de la historia del tiempo presente. El mantra solía ser no tanto la transcendentalidad del documento escrito, sino la quirúrgica distancia temporal para evitar la contaminación de la subjetividad del historiador, en este caso más grave cuanto más cercano en el tiempo era el objeto de estudio. Lejos parecían incluso, en aquel tiempo, las disertaciones y reflexiones de E.H. Carr sobre el continuo diálogo entre el historiador y su objeto de estudio y el nexo permanente entre el presente y el pasado en el proceso de construcción de conocimiento. El historiador, como el científico social, no puede ni debe evadirse de su tiempo y ha de ser plenamente consciente en su trabajo del velo preinterpretativo desde el que realiza su trabajo. $\mathrm{Y}$ en este sentido ha de proyectar, en $\mathrm{mi}$ modesta opinión, su horizonte ético a la hora de valorar y enjuiciar moralmente los procesos y los acontecimientos, pero ha de ser, asimismo, extraordinariamente riguroso y escrupuloso a la hora de aplicar el método científico al hacer ciencia.

¿Qué responsabilidad tenemos como historiadores en las repercusiones políticas, sociales, etc. de lo que narramos?

Los historiadores en la construcción de la verdad -las verdades- sobre el pasado desde el presente son cómplices y productos del tiempo en que viven. En la medida en que el oficio 
de historiador se ha profesionalizado, del mismo modo en que lo han hecho también las ciencias sociales, forman parte de una malla de construcción textual, de construcción de relatos, en cuya textura se concretan las conexiones entre el conocimiento y el poder. Sin menoscabar el debate en el seno de las ciencias sociales y en la historiografía la construcción de modelos analíticos y de relatos son filtrados y metabolizados desde la gubernamentalidad hasta configurar regímenes de veridicción. Del mismo modo, aquellos otros modelos analíticos y relatos que quedan en sus márgenes o en la invisibilidad de la frontera entre espacios y comunidades identitarias articulan formas de conocimiento y relatos fronterizos y alternativos. En ese sentido el etnocentrismo del pensamiento social occidental o la emergencia desde la condición postmoderna de pensamientos críticos desde el plano del pensamiento poscolonial y decolonial -entre otros-, permeables al quehacer de los historiadores, serían ilustrativos de la responsabilidad social de los historiadores y los científicos sociales desde su labor como comunidad epistémica. El propio Immanuel Wallerstein o Walter D. Mignolo indagan sobre la responsabilidad de los científicos sociales y los historiadores en las diferentes versiones del sistema mundo moderno como actores del jet stream del liberalismo. En particular los historiadores, artesanos de un saber ideográfico, desempeñarían un papel fundamental en la construcción de los relatos identitarios. Del mismo modo, podríamos evocar las reflexiones bien conocidas de Edward Saïd en torno al orientalismo y los orientalistas como instrumentos de poder en las prácticas del imperialismo y en la construcción de la otredad.

\title{
¿Debemos medir y, eventualmente, evitar aquellos temas que -en teoría-debilitan nuestras convicciones y fortalecen a los "adversarios"?
}

El debate académico y científico se ha de plantear desde la honestidad y el rigor, así como desde una dinámica de puertas giratorias que permitan un libre fluido de las ideas. Poner límites al debate sobre ideas al hilo de los prejuicios, los temas, los planeamientos conceptuales o las pautas metodológicas no puede conducir más que a la tibetanización del conocimiento. El debate abierto y honesto con el "adversario" no puede más que fortalecer al partícipe en el encuentro de ideas. Cuestionarse y ser cuestionado es parte fundamental del ejercicio intelectual de nuestra profesión. Por el contrario, limitarse conlleva la asunción del prejuicio y de la dogmatización, lo que navega a contracorriente del libre pensamiento y el mestizaje cultural.

\author{
Matteo RE \\ Universidad Rey Juan Carlos, España
}

\section{Describimos procesos internacionales y sus consecuencias, pero ¿es lícito hacer una valoración moral de éstos?}

Por lo general la historia se interpreta, no se juzga. Sin embargo, creo que hay determinados temas de estudio que sí pueden ser objeto de valoraciones morales.

En mi caso específico, al ocuparme de violencia política $-y$ en especial modo de terrorismo-, considero que una valoración moral no riñe con los dictámenes deontológicos del historiador. Digo esto, considerando la oportunidad de crear, en algunos determinados casos donde se empleó -o se sigue empleando- violencia terrorista, una contra-narrativa basada en la realidad y lejos de cualquier tipo de tergiversación de los hechos. Dicha contra narrativa tendrá el objetivo de equilibrar el discurso sectario de quienes perpetraban -o 
perpetraban - la violencia, evitando que su mensaje cale hondo en la sociedad.

Para lograr el objetivo que acabo de comentar, hace falta, tal y como sustenta Luis Castells -opinión que comparto-, "narrar una historia con rostro humano", pero al mismo tiempo "narrar un relato complejo". Estos dos factores probablemente serían suficientes para contar la verdad. Sin embargo, creo que la labor intelectual de un académico tiene que ir más allá de la mera narración de la verdad, tiene que cumplir con un ejercicio de valentía, denunciando las prácticas intimidatorias, ya no solo del terrorismo, sino también de su entorno más cercano. El peligro al que nos enfrentamos, al no comprometernos a fondo ética y moralmente contra el terrorismo, es que triunfe la interpretación de la lucha terrorista como acto romántico de autoinmolación para lograr un bien común. Tal y como decía Kaliayev, personaje principal de Los justos de Albert Camus para animar a sus compañeros anarquistas a la lucha: "Nosotros matamos para construir un mundo en el que nadie vuelva a matar nunca. Aceptamos ser criminales para que la tierra se cubra por fin de inocentes". En los estudios sobre terrorismo a nivel internacional es fundamental huir de esta percepción de luchadores por la patria o por la libertad ya que, al narrar acontecimientos lejanos temporalmente y físicamente, es más fácil que ese mensaje triunfe.

\section{¿Qué responsabilidad tenemos como historiadores en las repercusiones políticas, sociales, etc. de lo que narramos?}

Los historiadores tenemos una responsabilidad muy elevada sobre lo que contamos, especialmente si tenemos la posibilidad de acceder a los medios de comunicación. La palabra de un experto es amplificada por los periódicos y la televisión y tiene el poder de convencer, pero al mismo tiempo es más fácilmente atacable por las críticas de quien no comparte nuestra opinión. Tenemos que contar con el hecho de que hay ideas preconcebidas que difícilmente pueden modificarse, y que a menudo las redes sociales no hacen que complicar la labor de una narración histórica fehaciente y justa. Sin embargo, y a pesar de lo anteriormente dicho, nuestra labor es la de narrar e interpretar los hechos de manera fiel, aunque esa narración no guste a la platea.

\section{¿Debemos medir y, eventualmente, evitar aquellos temas que -en teoría- debili- tan nuestras convicciones, $y$ fortalecen a los "adversarios"?}

Creo que hay que contar la historia evitando omisiones. El relato siempre tiene puntos débiles, pero no por eso hay que ocultarlos. Es cierto que hay hechos que pueden fortalecer bastante a los "adversarios". En los estudios sobre terrorismo no ayudan el entramado del GAL en España, la Estrategia de la Tensión en Italia, las actuaciones violentas por parte de la policía para aniquilar a los militantes de la RAF en Alemania y, más en general, todas aquellas intervenciones represoras por parte del estado que superaron los límites consentidos por la ley. Sin embargo, ocultar los hechos siempre es un error. Lo que hay que hacer es, en mi opinión, matizarlos, pero en ningún caso silenciarlos. Según mi experiencia, los hechos que se suelen considerar como precipitantes - según la interpretación de Martha Crenshaw-, es decir aquellos acontecimientos que se consideran como favorecedores del aumento de un determinado conflicto armado, a menudo no son más que excusas que los terroristas suelen utilizar para justificar el uso de la violencia. Por lo tanto, sin necesidad de ocultarlos, hace falta explicarlos y desmontar así ese relato. 


\section{RELACIONES INTERNACIONALES}

Revista académica cuatrimestral de publicación electrónica Grupo de Estudios de Relaciones Internacionales (GERI) Universidad Autónoma de Madrid, España

www.relacionesinternacionales.info

ISSN 1699 - 3950

ff facebook.com/RelacionesInternacionales

twitter.com/RRInternacional 